\title{
PKM PENDAMPINGAN PEMASARAN UMKM IKATAN PENGUSAHA AISYIYAH DI KOTA MALANG
}

\author{
Muhammad Wildan Affan ${ }^{1}$, Dwi Irawan ${ }^{2}$ \\ Universitas Muhammadiyah Malang
}

\begin{abstract}
Muhammadiyah has formed the Aisyiyah Entrepreneurs Association which aims to accommodate the entrepreneurial activities of Aisyiyah members. But in its implementation there are several obstacles that occur that greatly hinder the development of its business. Among them are poor organizational culture, the use of basic local wisdom materials for products produced quite a bit, as well as marketing that does not take advantage of technological advances to make online sales. Optimization of the IPAS community, namely providing solutions to the constraints that occur through appropriate training and marketing assistance using technological advances includes understanding the importance of good organization marked by creating organizational structures, conducting online sales training both in terms of products and in terms of packaging in in order to support marketing to be able to compete in a wider market.
\end{abstract}

Keywords: UMKM; mobile commerce; marketing

\begin{abstract}
Abstrak
Muhammadiyah

telahmembentukIkatanPengusahaAisyiyah

yang

bertujuanuntukmengakomodirkegiatanberwirausahaanggotaAisyiyah.

Tetapidalampelaksanaannyaterdapatbeberapakendala yang terjadi yang sangatmenghambatperkembanganusahanya. Diantaranyaadalahbudayaorganisasi yang kurangbaik, penggunaanbahandasarkearifanlokaluntukproduk yang dihasilkancukupsedikit, sertapemasaran yang kurangmemanfaatkankemajuanteknologiuntukmelakukanpenjualan online.Optimalisasikomunitas IPAS yaitumemberikansolusiataskendala-kendala yang terjadimelaluipelatihan dan pendampinganpemasaran yang tepat dengan menggunakan kemajuan teknologi meliputi pemahaman pentingnya berorganisasi yang baik yang ditandai dengan pembuatan struktur organisasi, melakukan pelatihan penjualan secara online baik dari segi produk maupun dari segi pengemasan dalam rangka menunjang pemasaran untuk dapat bersaing dalam pasar yang lebih luas.
\end{abstract}

Kata kunci : UMKM; mobile commerce; pemasaran

\section{PENDAHULUAN}

Usaha Mikro, Kecil dan Menengah (UMKM) merupakansectorekonomi yang memilikiperan yang cukupbesardalampertumbuhanperekonomiannasional.

Salah satuperannyayaitupemenuhankebutuhanmasyarakatakansebuahprodukunggul, membukalapanganpekerjaanbaru dan meningkatkanpendapatan daerah. Berdasarkan data statistik, UMKM yang tersebar di Malang berada di kisaran 113.000 unit. Hal inimasihdapatdikatakantidakdapatmemenuhikebutuhanmasyarakatkota Malang yang mencapai 800 ribujiwa.

Muhammadiyahsebagai salah satuorganisasiterbesar di Indonesia yang juga memilikiperanandalammeningkatkanpertumbuhanekonomi,

membuatsebuahkomunitasIkatanPengusahaAisyiyah yang berada di bawahnaungan Majelis Ekonomi dan Kewirausahaan (MEK) Aisyiyah. Komunitas IPAS yang merupakankumpulandarianggotaaisyiyah yang telahmenjalankanusaha dan yang akanatauberkeinginanuntukmenjalankanusaha. Usaha yang dijalankan rata-rata masihdapatdikategorikansebagai UMKM.

Suatukomunitasdapatberjalandenganlancarapabilamemilikibudayakomunitas baik. Budayakomunitas yang baikdapatdilihatdaritingkat turn over pegawai yang ada, jikatingkat turn over tinggimakadapatdikatakanbahwabudaya yang adatidakbaik. Pada IkatanPengusahaAisyiyah, tingkat turn over 
pegawai yang adacukuptinggi, iniakansangatmenghambatkeberlangsungandarikegiatanusaha yang akanberdampak pada penurunankualitas dan penjualanusaha. Salah satupenyebab turn over yang tinggidikarenakanbelumadanyamanajemenoperasional yang baik, seperti job desk anggotaatau system operasionalprosedur.

$$
\text { IPAS yang telahmenjalakankomunitasnnyamempunyaibeberapahasilproduksi yang }
$$

memanfaatkankearifanlokal, salah satunyayaitumakanandenganbahandasarikan dan sayur. Namundalampelaksanaannyasering kali terkendala oleh kemampuansumberdayamanusia yang dimilikiuntukdapatmenhasilkanproduksesuai yang direncanakan. Hal inidikarenakananggota IPAS masihmemilikikemampuan yang rendah dan kurangnyapengalaman. Padahalpermintaanmasyarakatcukuptinggiakansuatuprodukunggulandaerah yang memanfaatkankearifanlokal dan gizi yang baik

$$
\text { Kemajuanteknologi yang cukuppesatmemaksa para }
$$

pelakuusahauntukdapatmenggunakansecaramaksimal agar tidaktergurus oleh pendatangbaru dan tetapdapatbersaingdenganpesaing yang telahada. Salah satupemanfaatannyayaitudalamhalpengelolaan dan cakupanpemasaran. Saatinitelahterdapattrenpemasarandenganmenggunakan media mobile marketplace, halinidirasakancukuptinggikebermanfaatan oleh beberapapengusaha yang telahmenggunakandikarenakanmasyarakattermudahkandalamproses jualbeli. Beberapapengusaha yang tergabung di IPAStelahmenggunakan e-commerce, tetapiterkendala oleh penerapanpenggunaanya. Sehinggasaatinipengusahamasihmenggunakanpemasaransecaratradisionalyaitumelaluimulutkemulut, acaraacara kemuhamadiyaan dan bazar yang diiadakan oleh cabang-cabangmuhammadiyah.

Berdasarkananalisissituasi di lingkunganmitra, makadapatdirumuskanbeberapapermasalahanyaitu :

1. Para

pengusaha

tergabungdalamkomunitasIkatanPengusahaAisyiyahtidakmemilikibudayaorganisasi yang baik

2. Para pengusaha

tergabungdalamkomunitasIkatanPengusahaAisyiyahbelummemilikisumberdayamanusia kompeten

3. Para pengusaha yang tergabungdalamkomunitasIkatanPengusahaAisyiyahbelumpaham pemasaran penjulan berbasis online

4. Para pengusaha yang tergabungdalamkomunitasIkatanPengusahaAisyiyahbelummemilikikemasan yang menunjangpenjualanberbasis online

\section{MATERI DAN METODE PELAKSANAAN}

Penyelesaianmasalah yang dalamikatanpengusahaaisyiyahdilakukandenganbeberapapendekatan yang dilakukansecaraserentakyaitu :

a. Metodediskusi, MenurutWina Sanjaya menyatakanbahwametodediskusidiartikansebagaicarauntukmenyampaikansebuahilmuuntukmemecahka npermasalahan.

b. Metodedemonstrasi, menurutMuhibbinSyah menyatakanbahwametodedemonstrasiadalahmetodepengajaran dilakukandenganmemperagakanurutansebuahkegiatansecaralangsungterhadapsebuahmateri. 
c. Berbasismobile marketplace, seluruhkegiatanpengabdianmasyarakatpadaanggota

IPASdilakukandenganmenggunakanpelatihan dan pendampingdarimasing-masingmobil marketplace yang akandigunakan

Keduametode di atas, dilaksanakanmelaluibeberapatahapanyaitu yang pertamasosialisasi, yang keduapeningkatankompetensi, yang ketigapelaksanapenjualan online dan yang terkahir monitoring dan evaluasi.

Tabel1. Tabel Kegiatan Pengabdian

\begin{tabular}{|c|c|c|c|c|}
\hline No. & JenisKegiatan & $\begin{array}{l}\text { Partisipasima } \\
\text { syarakat }\end{array}$ & Luarankegiatan & Solusimasalah \\
\hline 1. & Sosialisasi PPM & $\begin{array}{l}\text { UMKM IPAS } \\
\text { dan } \\
\text { menyiapkante } \\
\text { mpatpelatihan }\end{array}$ & $\begin{array}{l}\text { Pesertamemahamitujuan PPM dan } \\
\text { meningkatkanmotivasidalammengi } \\
\text { kuti agenda selanjutnya }\end{array}$ & $\begin{array}{l}\text { Melibatkanketua IPAS } \\
\text { dan } \\
\text { pemberianmotivasiuntuk } \\
\text { meningkatkankreatifitas }\end{array}$ \\
\hline 2. & $\begin{array}{l}\text { Pelatihan dan demo } \\
\text { manajemenoperasio } \\
\text { nal }\end{array}$ & $\begin{array}{l}\text { Sebagaipesert } \\
\text { a }\end{array}$ & $\begin{array}{l}\text { Pesertamemahamipentingnyastrukt } \\
\text { urorganisasi dan pembukuan yang } \\
\text { baik }\end{array}$ & $\begin{array}{l}\text { Pembinaanpembuatanpe } \\
\text { mbukuansederhana dan } \\
\text { strukturorganisasi }\end{array}$ \\
\hline 3. & $\begin{array}{l}\text { Pelatihan dan demo } \\
\text { pembuatanprodukba } \\
\text { handasarikanatausay } \\
\text { ur }\end{array}$ & $\begin{array}{l}\text { Sebagaipesert } \\
\text { a }\end{array}$ & $\begin{array}{l}\text { Pesertamemahamimanajemenopera } \\
\text { sionaluntukmenghasilkanproduk } \\
\text { yang berkualitas }\end{array}$ & $\begin{array}{l}\text { Demonstrasiproduksi dan } \\
\text { pembuatan SOP } \\
\text { mutuprodukbahandasarik } \\
\text { anatausayur }\end{array}$ \\
\hline 4. & $\begin{array}{l}\text { Pelatihanpenggunaa } \\
\text { nmobile commerce }\end{array}$ & $\begin{array}{l}\text { Sebagaipesert } \\
\text { apelatihan }\end{array}$ & $\begin{array}{l}\text { Pesertamemahamikemajuanteknolo } \\
\text { gi dan pemanfaatanmobile } \\
\text { commerce }\end{array}$ & $\begin{array}{l}\text { Pembuatandesainkemasa } \\
\mathrm{n} \\
\text { desainpemasaranmelalui } \\
\text { mobile commerce }\end{array}$ \\
\hline 5. & Pelaksanaankegiatan & $\begin{array}{l}\text { Sebagaiwiraus } \\
\text { aha }\end{array}$ & $\begin{array}{l}\text { Pesertamelakukanpenjualanmenggu } \\
\text { nakan marketplace }\end{array}$ & Pendampingan \\
\hline 6. & $\begin{array}{l}\text { Monitoring } \\
\text { Evaluasi }\end{array}$ & $\begin{array}{l}\text { Mendampingit } \\
\text { im PPM }\end{array}$ & Melakukanmonevpenjualan & Pendampingan \\
\hline
\end{tabular}

Sumber : Data diolah 2019

\section{HASIL DAN PEMBAHASAN}

Kegiatan pengabdian kepada masyarakat dilaksanakan pada hari Sabtu, 26 Oktober 2019 di Panti Asuhan Putri Aisyiyah, Kec. Lowokwaru, Kota Malang. Kegiatan ini dihadiri oleh anggota Ikatan Pengusaha Aisyiyah Kota Malang sebagai mitra kegiatan pengabdian sebanyak 24 orang yang rata-rata telah memiliki usaha. Tim pengabdian membagi kegiatan ini menjadi beberapa kegiatan untuk memberikan pengabdian yang sangat dirasakan manfaatnya oleh mitra. Tahapan tersebut sebagai berikut :

1. Tahapan pra pelaksanaan berupa koordinasi dengan berbagai pihak, diantaranya

a. KegiataninimerupakanbentukawaldarimenjalinhubungandenganIkatanPengusahaAisyiyah sebagaipihakmitra 
sebelumnyatelahbersediauntukdijadikansebagaiwadahpengabdiankepadamasyarakat.

Koordinasiawaladalahmemintaizin yang sifatnyalaporanbahwaakanmelaksanakanpengabdian di

ikatanpengusahaaisyiyahkepadaibu Sri Wibawani WA, Dra., M.Si., Ak., CA selakuketuaMajelisEkonomiAisyiyah (MEA) sebagaiorganisasi yang menaungi IPAS.

Koordinasiinimemberikangambaranbahwaorganisasi IPAS

memangsangatmembutuhkantambahankeahliandalammengembangkanusahanya agar

tetapdapatbersaingdenganmeningkatkanpesaingsertakemajuanteknologi yang ada .

Sehinggadiharapkandenganadanyapengabdian di IPAS dapatmenjagaeksistensikomunitasitusendiri.

b. Koordinasiselanjutnyadihadiri oleh para pengusul program pengabdiandenganbeberapaperwakilandaripihakmitrayaitu salah satunyaketua IPAS IbuMarwiyahSoediyono. Koordinasiinimenjelaskansecararincisituasi yang adadalamikatanpengusahaaisyiyah, yang salah satunyaadalahkurangnyakreatifitasdalammemanfaatkankearifanlocaldalammenghasilkanproduk produkunik dan dapatbersaingsertakurangnyapemanfaatanteknologidalammenunjangpenjualan. Oleh karenaitupengabdianinidisambutdenganantusias dan harapan yang tinggi. Selainitu, koordinasiinimembuahkanhasilmengenai para yang akandiundanguntukmengikutipelatihansekitar 30 orang yang terdiridariberbagaicabangaisyiyah di Malang dan pemateri yang akandijadikansebagainarasumberutamayaitu Bu Eni serta para pengusul yang akanmempresentasikanmasing-masingkeahliannyamengenaipenjualan online dan branding.

Lokasipelatihan yang disepakatiuntukmelaksanakanpengabdianadalah di

PantiAisyiyahcabangLowokwaru Malang

2. Tahapan pelaksanaan

Pelaksanaan kegiatan ini dilakukan dengan pemaparan materi - materi mengenai pemasaran suatu produk. Pemaparan materi ini dari berbagai referensi yang relevan dengan usaha mikro kecil dan menengah, yang berfokus pada bagaimana suatu usaha dapat menyiapkan berbagai strategi dalam menghadapi persaingan yang cenderung mengarah kepada kebermanfaatan teknologi. Pada sesi ini, anggota ikatan pengusaha aisyiyah sebagai mitra yang hadir sangat antusias mendengar setiap pemaparan oleh pemateri yang diiringi dengan berbagai pertanyaan untuk dijadikan bahan diskusi.

Setelah diberikan pemaparan materi mengenai pemasaran suatu produk, maka masuk ke acara ini dari kegiatan pengabdian yaitu untuk menunjang usaha dari anggota ikatan penguasaha aisyiyah dengan mulai diadakan kegiatan diskusi untuk membahas keadaan, kendala, dan strategi yang tepat untuk meningkatkan usaha anggota mitra. Pada sesi ini juga dimeriahkan dengan adanya barang yang telah dibawa oleh anggota mitra untuk didiskusikan dan sekaligus dipasarkan kepada anggota mitra lainnya. 


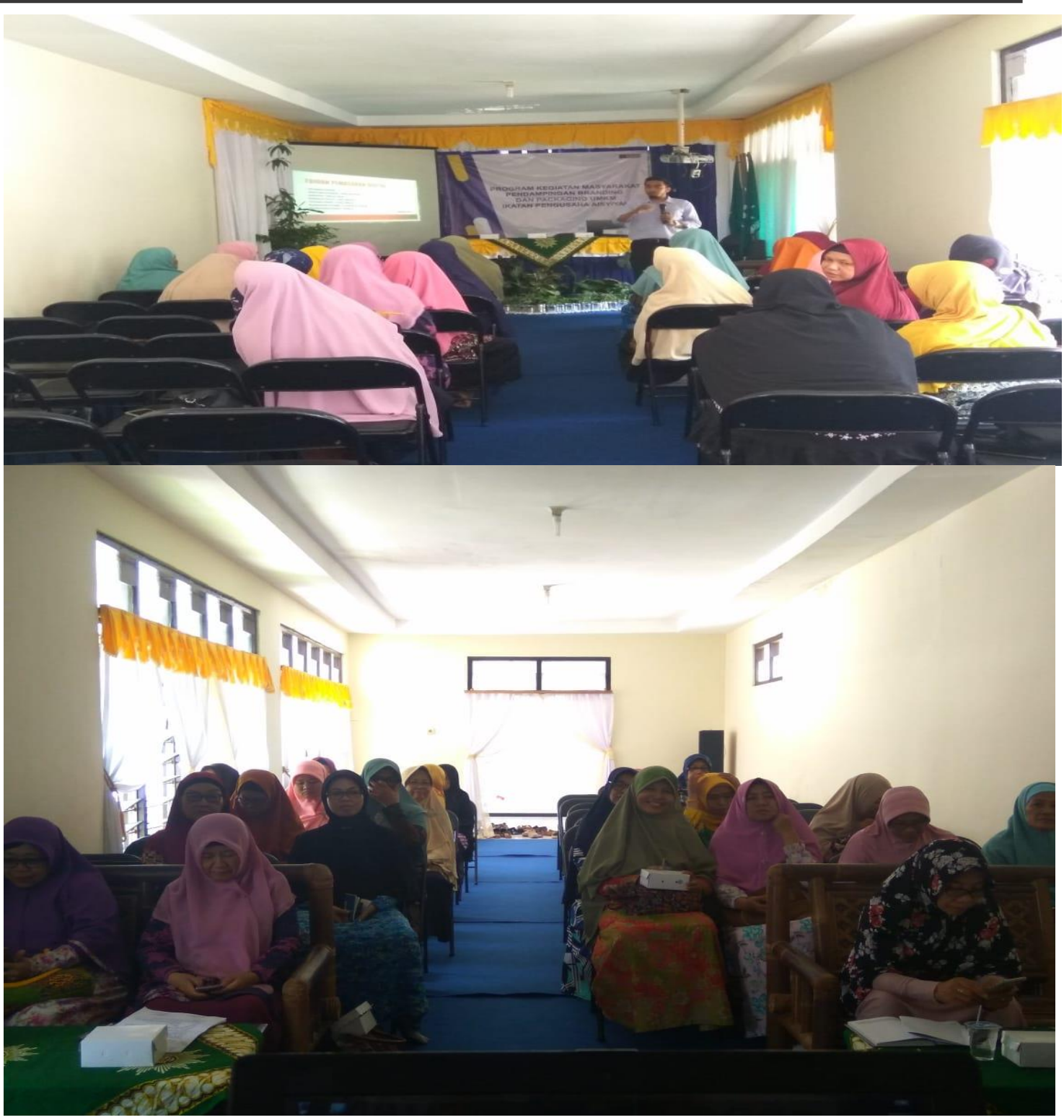




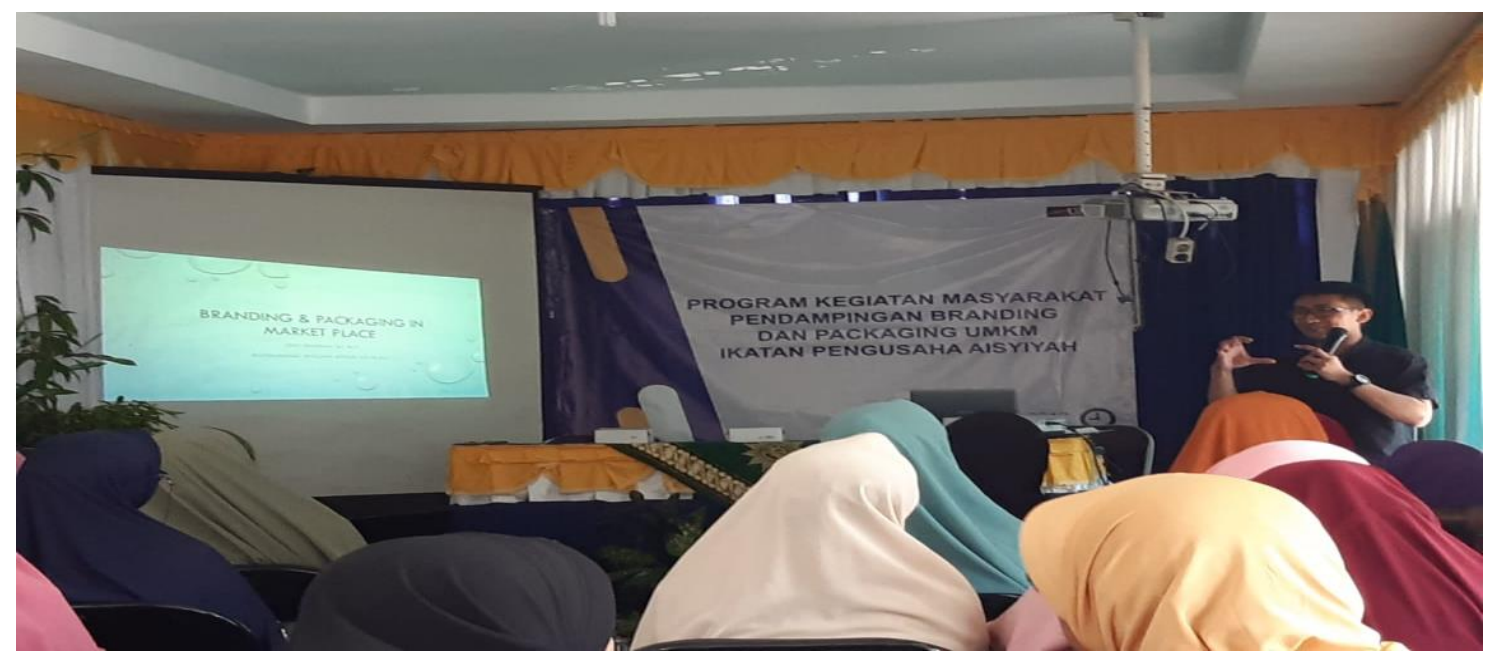

Gambar 1. Pelaksanaan pengabdian

3. Tahapan akhir pelaksanaan

Setelah melakukan pemaparan materi dan mendiskusikan barang-barang hasil usaha dari anggota mitra, tim pengabdian memberikan pendampingan untuk dapat menjalankan strategi yang telah didiskusikan sebelumnya. Hal ini sangat disambut baik dengan banyaknya permintaan diskusi melalui sosial media untuk hal-hal yang mungkin tidak dapat tertampung pada saat pelaksanaan, berupa permintaan pendampingan pembuatan logo suatu produk yang akan sangat menunjang untuk kegiatan pemasaran dari produk tersebut. Untuk menampung kegiatan pendampingan tersebut dan juga sebagai bentuk pemasaran dalam memanfaatkan kemajuan teknologi, maka tim pengabdian membuat group sosial media.

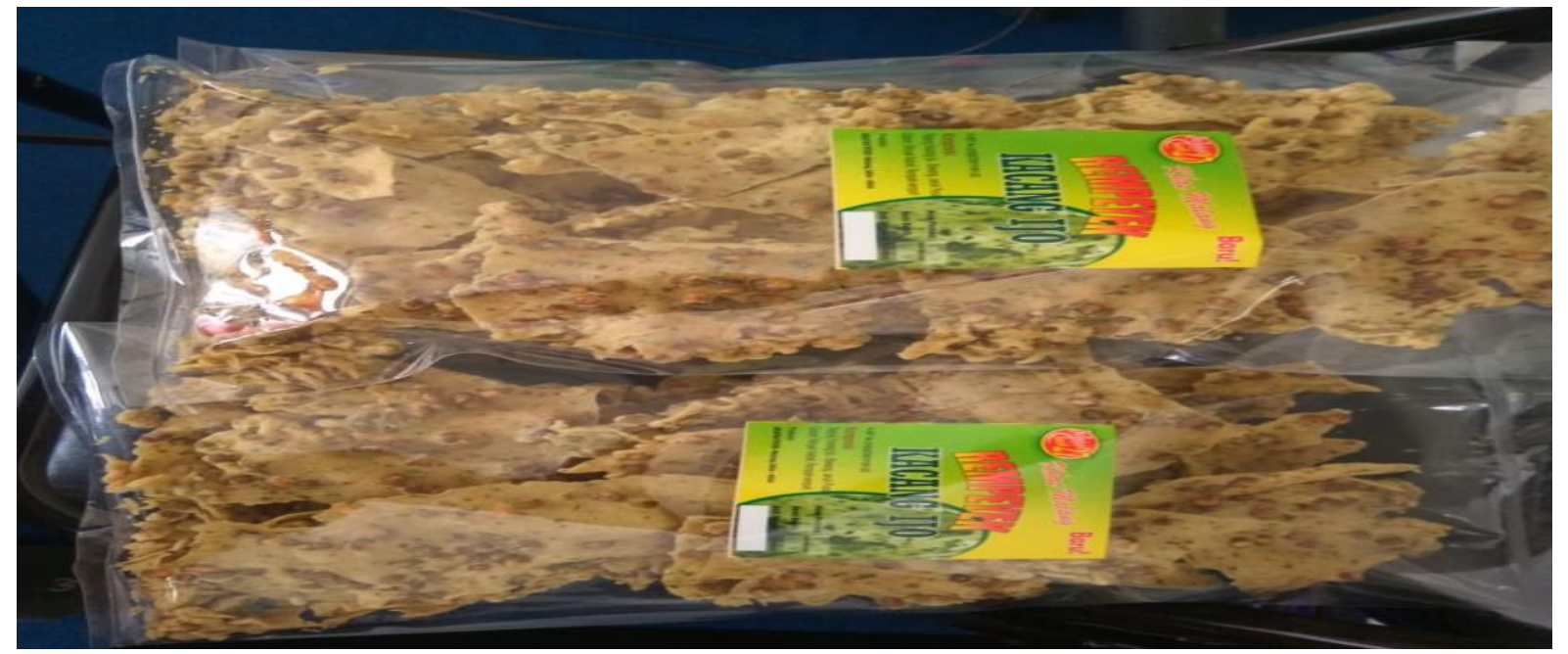




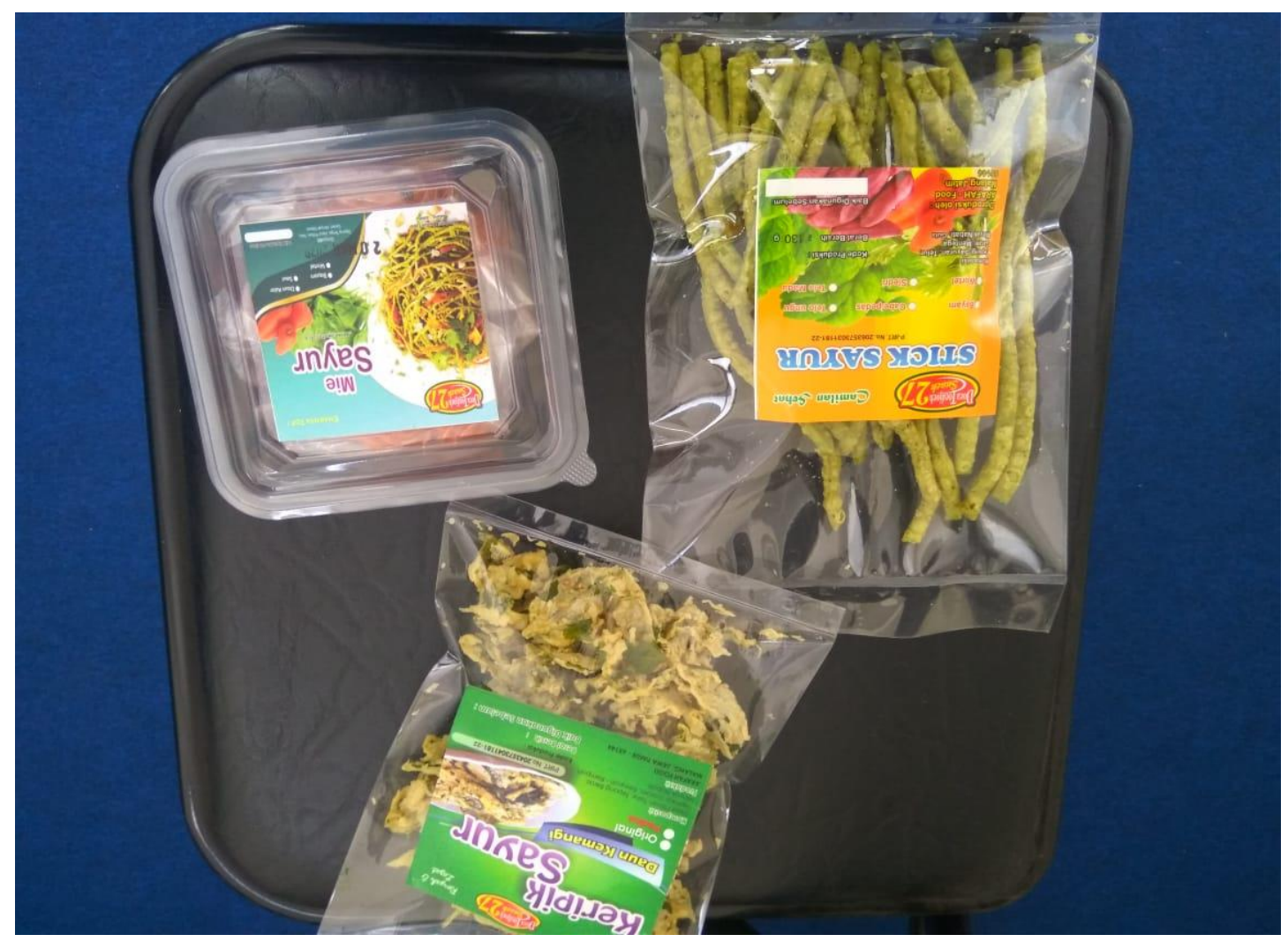

\section{Gambar 2. Produk UMKM}

\section{KESIMPULAN DAN SARAN}

Kegiatanpengbdiankepadamasyarakat

(PKM)

sudahdilakukandimulai

dari kegiatan koordinasimenyeluruhuntukmenjaminkelancarandarikegiatanpengabdian, pelaksanaan pengabdian berupa pemaparan materi dan diskusi permasalah mitra, serta diakhiri dengan melakukan pengdampingan dalam menghadapi masalah yang telah didiskusikan sebelumnya. Hasil pelaksanaan anggota ikatan pengusaha aisyiyah sangat tertarik untuk dapat mengembangkan usahanya dengan melakukan berbagai strategi pemasaran khusunya dengan memanfaatkan kemanjuan teknologi. Namunterdapatberbagaikendala yang dihadapiyaitutidak mudahnya merubah kegitan operasional yang sebelumnya telah terbangun dari masing-masing anggota mitra berupa model pengelola organisasinya maupun dari sisi modal. Saran yang mungkindapatdilaksanakanadalah anggota yang telah mengikuti kegiatan pengabdian mengusahakan untuk berusaha merubah pola kerja secara bertahap dari tradisional menjadi modern dengan berbagai kemajuan teknologi khsusnya pemasaran.

\section{REFERENSI}

Wina Sanjaya. 2006. Strategipembelajaranberorientasistandar proses pendidikan. Jakarta: Kencana Muhibbin, Syah. 2000. PsikologipendidikandenganPendekatanBaru. Bandung: RemajaRosdakarya 